\title{
Myxedema madness complicating postoperative follow-up of thyroid cancer
}

Yanina J. Morosán Allo', Melanie Rosmarin', Agustina Urrutia', Maria Cristina Faingold', Carla Musso', Gabriela Brenta'

\section{SUMMARY}

Although hypothyroidism is associated with an increased prevalence of psychiatric manifestations, myxedema madness is rarely observed. We report the case of a 62-year-old woman with no prior history of psychiatric disorders, who presented to the emergency department with psychomotor agitation 6 weeks after total thyroidectomy for papillary thyroid cancer. Serum thyroid stimulating hormone (TSH) on admission was $62.9 \mathrm{mlU} / \mathrm{L}$ and free T4 was $<0.35 \mathrm{ng} / \mathrm{dL}$, indicating severe hypothyroidism. After ruling out other possible causes, the diagnosis of myxedema madness was considered; hence, antipsychotic drug treatment and intravenous levothyroxine were prescribed. Behavioral symptoms returned to normal within 4 days of presentation, while levels of thyroid hormones attained normal values 1 week after admission. Recombinant TSH (Thyrogen ${ }^{\circledR}$ ) was used successfully to prevent new episodes of mania due to thyroid hormone withdrawal in further controls for her thyroid cancer. This case illustrates that myxedema madness can occur in the setting of acute hypothyroidism, completely reverting with levothyroxine and antipsychotic treatment. Recombinant TSH may be a useful tool to prevent myxedema madness or any severe manifestation of levothyroxine withdrawal for the follow-up of thyroid cancer. Arch Endocrinol Metab. 2015;59(4):359-63

\author{
1 Servicio de Endocrinologia \\ y Metabolismo, Unidad \\ Asistencial Dr. Cesar Milstein, \\ Buenos Aires, Argentina \\ Correspondence to: \\ Gabriela Brenta \\ Department of Endocrinology \\ and Metabolism \\ César Milstein Hospital \\ La Rioja 951 Buenos Aires, Argentina \\ gbrenta@gmail.com \\ Received on May/1/2014 \\ Accepted on July/23/2014 \\ DOI: 10.1590/2359-3997000000090
}

\section{INTRODUCTION}

$\mathrm{H}$ ypothyroidism is a clinical syndrome resulting from a deficiency in thyroid hormone. Clinical manifestations are varied, most characteristic are: fatigue, intolerance to cold temperatures, dry skin, hair loss, nonpitting edema, facial puffiness and constipation (1). Furthermore, overt hypothyroidism is associated with multiple psychiatric disorders among which psychosis, depression and affective disorders are the most frequent (2). Although maniac episodes are related to hyperthyroidism, they can also occur with hypothyroidism (3). In this setting, the acute deprivation of thyroid hormone in order to assess thyroglobulin during the follow-up of thyroid cancer may increase the risk of psychiatric manifestations.

We present the case of a patient who developed signs and symptoms of psychosis as a consequence of acute hypothyroidism after thyroidectomy for thyroid cancer. We discuss the therapeutic approach to this case and also propose a strategy to prevent this outcome.

\section{CASE REPORT}

A 62 year old woman was admitted to our hospital for psychomotor agitation lasting over 24 hours. Her medi- cal history included hypertension and a total thyroidectomy for papillary thyroid carcinoma performed 6 weeks prior to admission. She had been instructed to begin levothyroxine replacement 4 weeks after thyroidectomy, soon after radioactive iodine (RAI) ablation with a dose of $100 \mathrm{mCi}$. The whole body scan (WBS) and thyroglobulin during hypothyroid status were both negative. According to the American Joint Committee on Cancer (AJCC) TNM system, the patient was classified as Tl N0 M0, Stage I. When admitted to the hospital with psychomotor agitation, the patient was not under levothyroxine replacement therapy, because she had not followed the medical indications after RAI ablation. The family denied a history of psychiatric disorders.

One week before admission the patient began with inappropriate behavior. She said that she was writing a mystical book whose content was dictated by an inner voice. She also screamed and hit her family members as well as herself.

Her physical examination revealed a blood pressure of $140 / 70 \mathrm{mmHg}$, a heart rate of $62 \mathrm{bpm}$, and a temperature of $36^{\circ} \mathrm{C}$. Her face appeared puffy, with macroglossia, and bilateral eyelid edema. Routine laboratory tests, CT, MRI, and EEG showed no ab- 
normal findings. On psychiatric evaluation, the patient demonstrated verbal and physical hostility, delusions, nonproductive hyperbulia and stereotyped movements, tachylalia with polymorphous speech, delusional ideation and insomnia. Haloperidol 2.5 $\mathrm{mg} /$ day, lorazepam $2.5 \mathrm{mg} /$ day and levomepromazine $12.5 \mathrm{mg} /$ day were administered. High doses of these drugs were necessary to achieve optimal effect. Thyroid test results were: TSH: $62.9 \mathrm{mIU} / \mathrm{L}$, free T4: $<0.35 \mathrm{ng} / \mathrm{dL}$, total T4: < $1 \mathrm{ug} / \mathrm{dL}, \mathrm{T} 3: 70 \mathrm{ng} /$ $\mathrm{dL}$, consistent with severe hypothyroidism. Hence, the diagnosis of myxedema madness was considered and an initial intravenous bolus of 200 ug of levothyroxine was administered. During the following days she received an oral combination of triiodothyronine $20 \mathrm{ug} /$ day and levothyroxine $100 \mathrm{ug} / \mathrm{d}$. The fourth day of treatment the patient appeared fully oriented, calm, and denied auto and heteroaggresive ideation. One week after beginning thyroid replacement, new thyroid function tests were performed. Results were: TSH: $39.4 \mathrm{mU} / \mathrm{L}$, TT4: $10.4 \mu \mathrm{g} / \mathrm{dL}$, free T4: $1 \mathrm{ng} / \mathrm{dL}, \mathrm{T} 3: 1.9 \mathrm{ng} / \mathrm{dL}$. By then, the patient had already experienced some clinical improvement and her facial puffiness and edema had disappeared. She was finally discharged with $150 \mathrm{ug} /$ day of levothyroxine (Figure 1). Two weeks after discharge, she returned to the clinic for her follow-up visit with new thyroid function tests revealing TSH: $16.1 \mathrm{mU} / \mathrm{L}, \mathrm{TT} 4: 13.9$ $\mu \mathrm{g} / \mathrm{dL}$, free T4: $1.8 \mathrm{ng} / \mathrm{dL}, \mathrm{T} 3: 0.9 \mathrm{ng} / \mathrm{dL}$. She was still under psychiatric treatment and the dose of the antipsychotic drugs was being tapered progressively. Four months after discharge, antipsychotic treatment was stopped definitively due to complete remission of her psychiatric disorder. The treatment regimen is summarized in table 1.

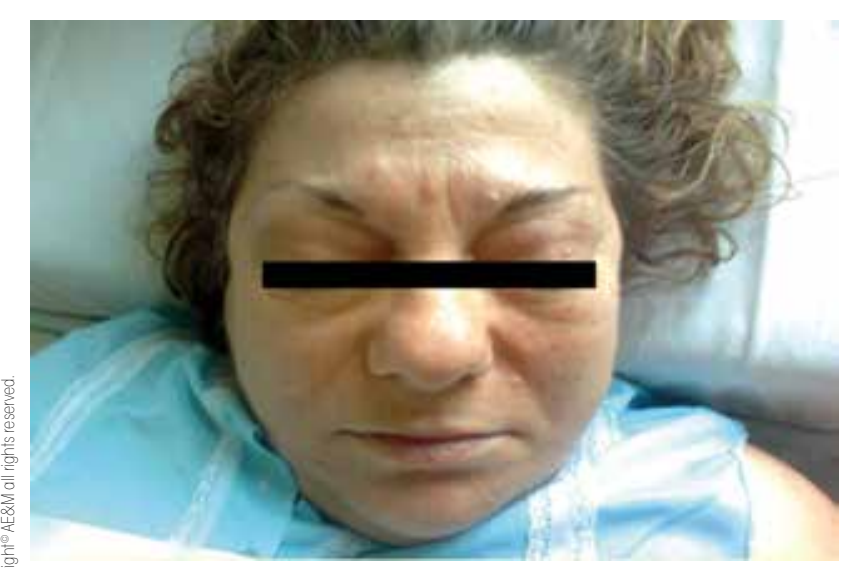

Figure 1. Patient's clinical presentation at hospital admission.
Table 1. Treatment

\begin{tabular}{lccc}
\hline Treatment & Baseline & 3 months & Currently \\
\hline Thyroxine & 200 mcg I.V bolus & Thyroxine 175 & Thyroxine 133 \\
& Then triiodothyronine & mcg 5 days a & mcg 5 days a \\
0.20 mcg and & week and 133 & week and 175 \\
thyroxine 100 mcg a & mcg 2 days a & mcg 2 days a \\
day, P0 & week & week \\
Antipsychotics & Haloperidol 2.5 mg a & Discontinued by & The patient was \\
& day P0 & her psychiatrist & discharged by \\
& Lorazepam 2.5 mg a & a month ago & her psychiatrist \\
& day P0 & & \\
& Levomepromazine & & \\
12.5 mg a day, P0 & & \\
\hline
\end{tabular}

Increasing levels of thyroxine were administered to the patient, with improvement of hypothyroid symptoms. Psychiatric symptoms were improved after a few weeks, until psychiatric treatment was no longer required.

PO: Per Os.

During her subsequent visits, the thyroid profile while on $150 \mathrm{mcg}$ of levothyroxine was: TSH $<0.03$ $\mathrm{mU} / \mathrm{L}$, FT4: $1.76 \mathrm{ng} / \mathrm{dL}$. Her stimulated thyroglobulin and WBS measured 6 months post ablation dose were performed on the $5^{\text {th }}$ and $8^{\text {th }}$ day respectively after receiving the first dose of recombinant human TSH $\left(\right.$ Thyrogen $\left.^{\circledR}\right)$. This strategy was implemented considering that the patient might repeat a new episode of myxedema madness once she developed overt hypothyroidism after levothyroxine deprivation. With TSH $>75 \mathrm{mU} / \mathrm{L}$, stimulated thyroglobulin was < $1 \mathrm{ng} /$ $\mathrm{mL}$ with negative thyroglobulin antibodies; WBS was negative. During the remaining follow-up she had no psychiatric complications and no further maniac episodes, remaining emotionally stable until present.

\section{DISCUSSION}

During the second half of the $19^{\text {th }}$ century, the study of hypothyroidism led to a considerable amount of scientific information on this disease. William Gull (4) was the first one to describe hypothyroidism in adults in 1874. A few years later, William Ord (5), coined the term "myxedema" to describe nonpitting edema in patients with this disorder. In 1888, hypothyroidism was first associated with psychosis by the Committee of Myxoedema of the Clinical Society of London (6). The term "myxedema madness" was introduced in the literature by Asher (7) in 1949, when he presented 14 cases of patients with myxedema and psychosis.

To date, the pathophysiology underlying the association between psychosis and hypothyroidism has not been fully elucidated. However, low T3 levels due to hypothyroidism may affect brain regions involved in 
mood regulation such as the amygdala and hippocampus, where high concentrations of $\mathrm{T} 3$ receptors have been reported (8). Recent advances in neuroimaging techniques have provided further insight regarding the site of action of thyroid hormones in the brain. Bauer and cols. (9), studied glucose metabolism in the brain of hypothyroid patients by means of PET/CT scan before and after replacement treatment with levothyroxine. They found decreased metabolic activity in multiple sites of the brain when compared to healthy controls. These findings were significant in the perigenual and subgenual anterior cingulate cortex, posterior cingulate cortex, amygdala and hippocampus, all of which are neural centers related to emotions, integration of information and memory regulation. Furthermore, after levothyroxine treatment, brain glucose metabolism was restored to normal.

Several hypotheses have been formulated to explain the role of hypothyroidism in the central nervous system (CNS), leading to psychiatric disorders. The potential mechanisms of action include the interaction of thyroid hormones and neurotransmitters. It has been shown that an enhanced activity of the enzyme tyrosine hydroxylase is related to increased concentrations of dopamine (DA) in the brain of hypothyroid rats, thereby leading to the manifestation of mania due to monoamine excess (10-12). Another hypothesis is based on serotonin activity. It has been reported that in the limbic system of the rat, hypothyroidism can cause a decrease in serotonin with the consequent up-regulation of dopamine postsynaptic receptors and increased dopamine activity in the brain, resulting in maniac symptoms $(12,13)$. Furthermore, thyroid hormones have a modulating impact on the brain catecholamine system, regulating $\beta$-adrenergic receptor sensitivity, so that changes in hormone levels, as seen in hypothyroidism, might increase catecholamine action with major risk of mania in vulnerable individuals (14). Therefore, the influence of an impairment of the thyroid system on neurotransmitters (particularly serotonin and norepinephrine), which play a major role in the regulation of mood and behavior, may contribute to the mechanisms of mood modulation $(12,15)$.

Thvilum and cols. (16) have reported that hypothyroidism is associated with an enhanced prevalence of psychiatric morbidity. This is reflected by the fact that hypothyroid patients are exposed to an increased risk of hospitalization with psychiatric diagnoses and being treated with antipsychotics, antidepressants, and anxio- lytics, both before and after the diagnosis of hypothyroidism. Although hypothyroidism is mainly associated with depression (17), other psychiatric manifestations include delusions, visual and auditory hallucinations, loose associations and paranoia (16). It has been shown that patients with subclinical hypothyroidism may also present disorders of thought, suggesting that psychosis in some cases is not related to advanced disease (18). Although reports on several cases of myxedema madness have illustrated that psychosis is usually preceded by months or years of clinical symptoms of hypothyroidism $(1,7,19-25)$, there have been few cases reported in the literature $(26,27)$ where psychiatric manifestations occurred in the setting of acute overt hypothyroidism (Table 2). Similarly, our patient also presented symptoms of mania in the context of a hypothyroid state of recent onset. Once the diagnosis of psychosis is established, thyroid replacement has to be initiated. Symptoms usually remit about 1 week after starting appropriate thyroid replacement (28). In their case, Stowell and Barnhill (26) started treatment with $100 \mu \mathrm{g}$ of intravenous T4 b.i.d. plus oral risperidone, reporting that at day 6 the patient no longer had symptoms of mania. Our patient initially received $200 \mu \mathrm{g}$ of T4 intravenously, followed by a combination of T3 and $\mathrm{T} 4$ given orally. The combination of T4 and T3 has been reported to benefit some patients with myxedema madness (29). As in most reported cases, our patient

Table 2. Evolution and degree of hypothyroidism in reported patients with myxedema madness

\begin{tabular}{lcccc}
\hline Author & $\begin{array}{c}\text { Cases } \\
\text { (number) }\end{array}$ & $\begin{array}{c}\text { Age } \\
\text { (years) }\end{array}$ & $\begin{array}{c}\text { Evolution of } \\
\text { hypothyroidism }\end{array}$ & $\begin{array}{c}\text { Baseline } \\
\text { TSH } \\
\text { (mIU/mL) }\end{array}$ \\
\hline $\begin{array}{l}\text { Heinrich and } \\
\text { Grahm (1) }\end{array}$ & 1 & 73 & Chronic & 43.79 \\
Asher (7) & 13 & $33-73$ & NS & NS \\
Mahendran (20) & 1 & 25 & Chronic & NS \\
Chalk (21) & 1 & 15 & Chronic & 240 \\
Levitte (22) & 1 & 40 & Chronic & 64 \\
$\begin{array}{l}\text { Chung (23) } \\
\text { Reed and Bland }\end{array}$ & 1 & 12 & Chronic & 92 \\
(24) & 1 & 35 & Chronic & $>40$ \\
$\begin{array}{l}\text { Balldin and cols. } \\
\text { (25) }\end{array}$ & 1 & 54 & NS & 7 \\
$\begin{array}{l}\text { Stowell and } \\
\text { Barnhill (26) }\end{array}$ & 1 & 35 & Acute & $>150$ \\
$\begin{array}{l}\text { Colombo and } \\
\text { cols. (27) }\end{array}$ & 1 & NS & Acute & 229 \\
\hline
\end{tabular}

NS: not specified. 
was also treated with antipsychotic drugs. However, this therapy was discontinued shortly after and until present the patient remains off antipsychotic treatment. Furthermore, while the patient responded favorably in the first week of treatment with antipsychotic drugs, the speed of recovery and lack of recurrences during follow-up could also be attributed to the prompt reversal of hypothyroidism with intravenous levothyroxine.

One of the uncertainties faced when monitoring papillary carcinoma in this patient is the high chance of new psychiatric episodes during the potential interruption of levothyroxine treatment. As an alternative to avoid severe hypothyroidism and possible major psychiatric manifestations, we resorted to recombinant TSH $\left(\right.$ Thyrogen $\left.^{\circledR}\right)$. In fact, it has been proposed that in certain patients with hypopituitarism, ischemic heart disease, a history of "myxedema madness", weakness due to advanced disease, or inability to elicit TSH elevation due to continued production of thyroxine by the thyroid remnant or metastatic tumor, recombinant TSH is the only acceptable option $(30,31)$. In our experience, this patient with previous myxedema madness upon overt acute hypothyroidism had no further manifestations of psychiatric disorders when TSH elevation was elicited by recombinant TSH $\left(\right.$ Thyrogen $\left.^{\circledR}\right)$.

\section{CONCLUSIONS}

Our patient had no previous psychiatric history and in her case, the trigger identified was acute postsurgical hypothyroidism. Although the pathophysiology of myxedema madness has not been well elucidated, the lack of thyroid hormones at sites of mood regulation in the central nervous system might explain the psychotic episode.

Due to her underlying disease, our patient would have required the interruption of hormone replacement therapy to assess thyroglobulin levels. Instead, we used recombinant TSH (Thyrogen ${ }^{\circledR}$ ) and the levels of $\mathrm{T} 4$ and $\mathrm{T} 3$ remained stable while TSH increased to the desired levels without subsequent psychiatric manifestations. The patient remained free of disease and had no further episodes of mania.

Although the use of recombinant TSH $\left(\right.$ Thyrogen $\left.^{\circledR}\right)$ in the management of thyroid cancer has been advocated to avoid the consequences of overt hypothyroidism, we could not find in the literature any report of its use in a patient with history of myxedema madness. Our findings demonstrate that myxedema madness can oc- cur shortly after thyroidectomy and that recombinant TSH can be useful to prevent new psychotic episodes during the follow up of thyroid cancer.

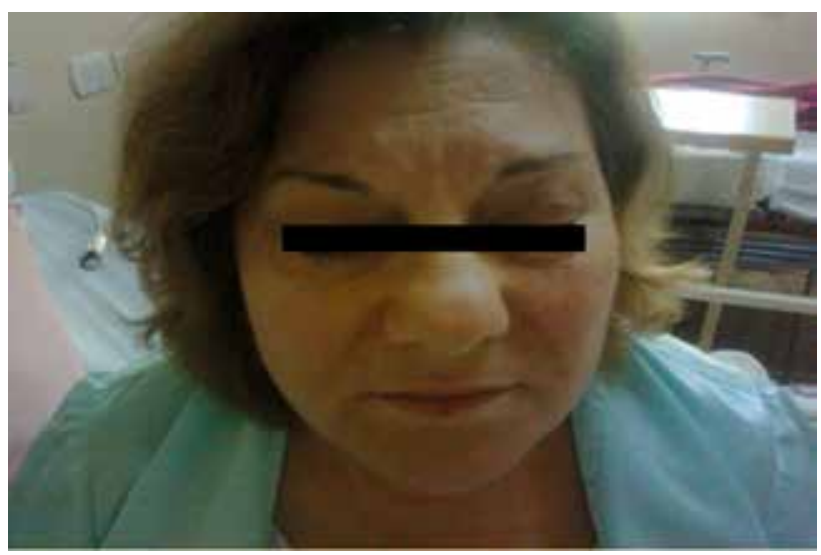

Figure 2. Patient's clinical improvement after one week of hormone replacement.

Disclosure: no potential conflict of interest relevant to this article was reported.

\section{REFERENCES}

1. Heinrich TW, Grahm G. Hypothyroidism Presenting as psychosis: myxedema madness revisited. Prim Care Companion J Clin Psychiatry. 2003;5(6):260-6.

2. Whybrow PC, Bauer M. Behavioral and psychiatric aspects in hypothyroidism: a fundamental and clinical text. 9th ed. Philadelphia: Lippincott Williams \& Wilkins; 2005. p. 842-50.

3. Sathya A, Radhika R, Mahadevan S, Sriram U. Mania as a presentation of primary hypothyroidism. Singapore Med J. 2009;50(2):e65-7.

4. Gull WW. On cretinoid state supervening in adult life in women. Trans Clin Soc Lond. 1874;7:180-5.

5. Ord WW. On myxedema. R Med Chir SocTrans. 1878;61:57-8.

6. Report of the Committee of the Clinical Society of London to investigate the subject of myxoedema. Trans Clin Soc Lond. 1888;21(Suppl):1-215.

7. Asher R. Myxoedematous madness. Br Med J. 1949; 2(4627):55562.

8. Ruel J, Faure R, Dussault JH. Regional distribution of nuclearT3 receptors in rat brain and evidence for preferential localization in neurons. J Endocrinol Invest. 1985;8(4):343-8.

9. Bauer M, Silverman DH, Schlagenhauf F, London ED, Geist CL, van Herle $\mathrm{K}$, et al. Brain glucose metabolism in hypothyroidism: a positron emission tomography study before and after thyroid hormone replacement therapy. J Clin Endocrinol Metab. 2009;94(8):2922-9.

10. Sato T, Imura E, Murata A, Igarashi N. Thyroid hormone-catecholamine interrelationship during cold acclimation in rats. Compensatory role of catecholamine for altered thyroid states. Acta Endocrinol (Copenh). 1986;113(4):536-42.

11. Goodwin G, Gary S. Bipolar disorder. Oxford: Health Press; 2004. p. 23-4.

12. Khemka D, Ali JA, Koch CA. Primary hypothyroidism associated with acute mania: case series and literature review. Exp Clin Endocrinol Diabetes. 2011;119(8):513-7. 
13. Crocker AD, Overstreet DH. Modification of the behavioural effects of haloperidol and of dopamine receptor regulation by altered thyroid status. Psychopharmacology (Berl). 1984;82(1-2):102-6.

14. Whybrow PC, Prange AJ Jr. A hypothesis of thyroid-catecholamine-receptor interaction. Its relevance to affective illness. Arch Gen Psychiatry. 1981;38(1):106-13.

15. Bauer M, London ED, Silverman DH, Rasgon N, Kirchheiner J, Whybrow PC. Thyroid, brain and mood modulation in affective disorder: insights from molecular research and functional brain imaging. Pharmacopsychiatry. 2003;36 Suppl 3:S215-21.

16. Thvilum M, Brandt F, Almind D, Christensen K, Brix TH, Hegedüs L. Increased psychiatric morbidity before and after the diagnosis of hypothyroidism: a nationwide register study. Thyroid. 2014;24(5):802-8.

17. Duntas LH, Maillis A. Hypothyroidism and depression: salient aspects of pathogenesis and management. Minerva Endocrinol. 2013;38(4):365-77.

18. Lehrmann JA, Jain S. Myxedema psychosis with grade II hypothyroidism. Gen Hosp Psychiatry. 2002;24(4):275-7.

19. Logothetis J. Psychotic behaviour as the indicator of adult myxedema. J Nerv Ment Dis. 1963;136(6):561-8.

20. Mahendran R. Hypomania in a patient with congenital familial hypothyroidism and mild mental retardation. Singapore Med J. 1999;40(6):425-7.

21. Chalk JN. Psychosis in a 15 year old hypothyroid girl: myxoedematous madness? Aust N Z J Psychiatry. 1991;25(4):561-2.
22. Levitte SS. Coexistent hypomania and severe hypothyroidism. Psychosomatics. 1993;34(1):96-7.

23. Chung A. Unusual presentation of myxoedema madness in a 12-year-old girl. Aust N Z J Psychiatry. 2010;44(3):292-4.

24. Reed K, Bland RC. Masked "myxedema madness". Acta Psychiatr Scand. 1977;56(5):421-6.

25. Balldin J, Berggren U, Rybo E, Kjellbo H, Lindstedt G. Treatment-resistant mania with primary hypothyroidism: a case of recovery after levothyroxine. J Clin Psychiatry. 1987;48(12):490-1.

26. Stowell CP, Barnhill JW. Acute mania in the setting of severe hypothyroidism. Psychosomatics. 2005;46(3):259-61.

27. Colombo GM, Aguglia G, Cicchinelli M. Emergency approach to psychosis in postoperative hypothyroidism. Minerva Endocrinol. 2007;32(3):237.

28. Tachman ML, Guthrie GP Jr. Hypothyroidism: diversity of presentation. Endocr Rev. 1984;5(3):456-65.

29. Bunevicius R, Kazanavicius G, Zalinkevicius R, Prange AJ Jr. Effects of thyroxine as compared with thyroxine plus triiodothyronine in patients with hypothyroidism. $\mathrm{N}$ Engl $\mathrm{J}$ Med. 1999;340(6):424-9.

30. Krausz Y, Uziely B, Nesher R, Chisin R, Glaser B. Recombinant thyroid-stimulating hormone in differentiated thyroid cancer. Isr Med Assoc J. 2001;3(11):843-9.

31. Schlumberger M, Ricard M, Pacini F. Clinical use of recombinant human TSH in thyroid cancer patients. Eur $\mathrm{J}$ Endocrinol. 2000;143(5):557-63. 